\title{
Peran Perawat dalam Peningkatan Kebijakan K3 di Rumah Sakit
}

\author{
Winda Sari Sinaga \\ Windasarisng1701@gmail.com
}

\section{Latar Belakang}

Rumah sakit ( RS ) merupakan salah satu tempat kerja yang berpotensi tinggi terjadinya kecelakaan kerja. Pada umumnya, angka terjadinya kecelakaan kerja di rumah sakit lebih tinggi dibandingkan pada tempat kerja lainnya. Tenaga kesehatan dan pekerja di rumah sakit mempunyai risiko lebih tinggi untuk terjadinya Penyakit Akibat Kerja ( PAK ) dan Kecelakaan Akibat Kerja ( KAK ) karena rumah sakit memberikan pelayanan kesehatan pada semua bidang dan semua jenis penyakit. Faktor utama yang menjadi penyebab terjadinya kecelakaan kerja di lingkungan rumah sakit adalah perilaku yang tidak aman ( unsafe action ) dan kondisi lingkungan kerja yang tidak baik ( unsafe condition ). Hal ini dipengaruhi banyak aspek, salah satunya kurangnya penerapan kebijakan Keselamatan dan Kesehatan Kerja ( K3 ) di rumah sakit.

Melihat tingginya angka kecelakaan kerja di lingkungan rumah sakit, pemerintah mengupayakan untuk meminimalisir terjadinya kecelakaan kerja dengan mengeluarkan kebijakan tentang penerapan Kesehatan dan Keselamatan Kerja di rumah sakit yang tercantum pada Undang-undang Nomor 23 Tahun 1992 dan Undang-undang Nomor 36 Tahun 2009.

Keselamatan kerja bagi petugas kesehatan dan keselamatan pasien menjadi hal yang paling utama menjadi tanggung jawab institusi pelayanan kesehatan seperti rumah sakit. Rumah sakit sebagai pemberi pelayanan kesehatan bagi seluruh masyarakat sudah seharusnya menyediakan dan menerapkan suatu kebijakan agar seluruh sumber daya manusia yang ada di rumah sakit dapat terlindungi, terjamin kesehatannya, keamanannya baik dari kecelakaan kerja maupun penyakit.

Penerapan kebijakan Keselamatan dan Kesehatan Kerja ( K3 ) di Rumah sakit, merupakan suatu upaya perlindungan kepada tenaga kerja dan orang lain yang memasuki lingkungan rumah sakit. Melalui penerapan kebijakan ini, diharapkan dapat memelihara dan meningkatkan derajat kesehatan bagi pasien, pendamping pasien, pengunjung, tenaga kesehatan dan lingkungan rumah sakit serta terciptanya lingkungan yang aman dan nyaman. 
Upaya penatalaksanaan $\mathrm{K} 3$ pada rumah sakit sangat didukung dari peran-peran tenaga kesehatan maupun non kesehatan yang bekerja dirumah sakit. Perawat merupakan salah satu komponen tenaga kesehatan yang bekerja dalam kurun waktu yang lama dan yang paling sering berinteraksi, melakukan kontak langsung dengan pasien. Penting bagi perawat untuk mampu memahami, menerapkan dan mendukung kebijakan $\mathrm{K} 3$ di rumah sakit ataupun di seluruh institusi pelayanan kesehatan. Perawat menjadi salah satu komponen utama dan kunci keberhasilan penerapan K3 di rumah sakit, melalui tangan perawat di setiap tindakan dapat meminimalisi terjadinya penularan penyakit dan kecelakaan kerja di rumah sakit. Maka dari itu, penting dan perlu bagi perawat untuk mengetahui peran yang harus dilakukan dan diterapkan saat bekerja di rumah sakit untuk meningkatkan angka keselamatan dan kesehatan kerja di rumah sakit.

\section{Metode}

Metode yang digunakan oleh penulis dalam jurnal ini adalah Literature review, dengan cara membaca, menganalisis bahan kajian yang relavan dengan pokok bahasan yakni peran perawat dalam peningkatan penerapan kebijakan K3 di rumah sakit.

Bahan kajian yang digunakan yakni berupa textbook, e-book, buku pedoman terkait, tesis dan jurnal online. Adapun jurnal dan referensi yang digunakan pada literature review ini, diterbitkan paling lama tahun 2012, dengan jumlah minimal yaitu 10 referensi.

\section{Hasil}

Berdasarkan hasil dari pencarian dan pengkajian literature dari berbagai sumber, didapatkan bahwa adanya hubungan yang berkaitan antara tingkat pengetahuan dan pemahaman perawat tentang $\mathrm{K} 3$ dengan keberhasilan penerapan $\mathrm{K} 3$ di rumah sakit dan adanya hubungan yang berkaitan antara sikap pencegahan KAK dan tindakan perawat yang mendukung penerapan K3 terhadap penerapan standar manajemen keselamatan kerja di rumah sakit.

Dari Jurnal Faktor psikologi dan perilaku dengan penerapan manajemen keselamatan dan kesehatan kerja rumah sakit, ( 2020 ). Dari hasilnya dapat disimpulkan bahwa terdapat hubungan antara faktor psikologi dan perilaku dengan penerapan manajemen K3RS di RSUD Pobundayan Kota Kotamobagu. RSUD Pobundayan Kota Kotamobagu telah menerapkan kebijakan K3RS namun tidak semua pegawai di rumah sakit mengetahui resiko kecelakaan kerja di rumah sakit. 
Dari Jurnal Analisa Komitmen Manajemen Rumah Sakit ( RS ) terhadap Keselamatan dan Kesehatan Kerja K3 pada RS Prima Medika Pemalang ( 2014 ), dapat disimpulkan bahwa mengetahui tentang K3 saja tidak cukup namun dibutuhkan pemahaman dan pelaksanaan lebih lanjut oleh karyawan rumah sakit agar mengetahui manfaat K3RS. Diperlukan peningkatan penerapan K3RS agar akebijakan K3 dapat terus berjalan di RS Prima Medika Pemalang.

Dari Jurnal Analisis Pelaksanaan Program Kesehatan Kerja di Puskesmas Sonder Kabupaten Minahasa ( 2018 ), dapat disimpulkan pelaksanaan program kesehatan kerja berjalan dengan baik dan untuk tingkat Puskesmas pentingnya pelayanan kesehatan lingkungan promosi kesehatan dan pelayanan pemberantasan penyakit menular dan tidak menular terlebih pada pekerja informal. Pelaksanaan program kesehatan kerja di Puskesmas Sonder masih kurang disebabkan karena Pengetahuan yang dimiliki tenaga kesehatan masih kurang dan untuk kader atau tenaga medis lainnya disarankan mengikuti pelatihan K3 terlebih dahulu agar memahami manfaat dari penerapan $\mathrm{K} 3$.

Dari Jurnal Perilaku Perawat dalam Penerapan Manajemen kesehatan dan Keselamatan Kerja K3 di Aceh ( 2017), disimpulkan pentingnya perilaku disiplin dari tenaga kesehatan dan non kesehatan yang bekerja di di rumah sakit yang mendukung penerapan K3 di rumah sakit. Perlunya pengembangan pengetahuan dan keterampilan di bidang manajemen keperawatan khususnya terkait K3 sehingga pelayanan yang diberikan lebih optimal dan berkualitas tanpa melupakan tingkat kesehatan dan keselamatan bagi pemberi asuhan keperawatan.

Dari Jurnal Faktor-faktor yang Berhubungan dengan Pelaksanaan Penerapan K3 Pada Tenaga Kesehatan Di RSIA Permata Sarana Husada Periode Februari 2015 ( 2017 ), dapat disimpulkan penerapak K3 di RSIA Permata Sarana Husada sudah terlaksana, namun masih kurang baik. Masih banyak tenaga kerja yang belum mendapatkan pengetahuan dan informasi mengenai kebijakan K3RS. Terdapatnya kaitan antara tingkat pengetahuan mengenai K3RS dengan upaya penerapan K3 di RSIA Permata Sarana Husada.

\section{Pembahasan}

Menurut WHO yang dilansir pada KMK RI No.1087/ MENKES/ SK /VII /2010 dikatakan bahwa Kesehatan Kerja merupakan program yang bertujuan untuk peningkatan dan pemeliharaan derajat kesehatan fisik, mental dan sosial yang setinggi-tingginya bagi pekerja di semua jenis pekerjaan, pencegahan terhadap gangguan kesehatan pekerja yang disebabkan oleh kondisi pekerjaan 
perlindungan bagi pekerja dalam pekerjaannya dari risiko akibat faktor yang merugikan kesehatan; dan penempatan serta pemeliharaan pekerja dalam suatu lingkungan kerja yang disesuaikan dengan kondisi fisiologi dan psikologisnya. Jadi dapat disimpulkan berdasarkan KMK RI No.1087 / MENKES / SK / VII / 2010 Kesehatan dan Keselamatan Kerja (K3) adalah upaya untuk memberikan jaminan keselamatan dan meningkatkan derajat kesehatan pekerja dengan cara pencegahan Penyakit Akibat Kerja (PAK), Kecelakaan Akibat Kerja ( KAK ) dan pengendalian bahaya di tempat kerja.

Kesehatan dan Keselamatan Kerja di Rumah sakit sendiri sebagai upaya dalam meningkatkan dan mempertahankan kesehatan yang dijamin untuk semua jabatan tenaga kerja Rumah Sakit, pasien, pendamping pasien, pengunjung rumah sakit, dan lingkungan rumah sakit sehingga dapat mengurangi angka terjadinya kecelakaan dan penyakit akibat kerja, sehingga dapat terciptanya lingkungan rumah sakit yang aman, nyaman, sehat, dan sejahtera. Upaya penatalaksanaan K3RS didukung dengan peran dari tenaga kesehatan maupun tenaga non kesehatan yang bekerja di Rumah Sakit.

Menurut Peraturan Menteri Kesehatan ( PMK ) No. 66 tahun 2016 pada pasal 2, menyatakan adapun yang menjadi tujuan pengaturan K3RS yaitu terselenggaranya keselamatan dan Kesehatan Kerja di Rumah Sakit secara optimal, efektif, efisien dan berkesinambungan bagi seluruh individu di rumah sakit; baik dari tenaga kesehatan, tenaga non kesehatan dan pasien beserta keluarga pasien. Keselamatan pasien (patient safety) menjadi bagian tanggung jawab terbesar dari rumah sakit dan tenaga kesehatan. Dimana keselamatan merupakan tanggung jawab dari pemberi jasa pelayanan kesehatan, salah satunya pemberi pelayanan keperawatan yakni oleh perawat. Perawatan yang diberikan pada pasien harus dengan dasar utama yakni memastikan dan menjamin keselamatan pasien dan keselamatan pasien harus menjadi focus utama dalam tatanan rumah sakit. Penerapan keselamatan pasien ini dapat terlaksana dalam setiap tugas dan tanggung jawab yang akan dilakukan oleh perawat.

Pentingnya tingkat pengetahuan dan pemahaman perawat mengenai penerapan Keselamatan dan Kesehatan Kerja di rumah sakit.

Pengetahuan seseorang tentang manajemen keselamatan dan kesehatan kerja di Rumah Sakit sangat penting pengaruhnya karena dengan pengetahuan dan pemahaman tentang penerapan K3 di rumah sakit akan meminimalis atau mengurangi penyakit akibat kerja ataupun kecelakaan akibat 
kerja. Pencegahan kecelakaan kerja dapat dilakukan dengan menerapkan pelaksanaan sesuai dengan SOP secara benar di tempat kerja dan penggunaan alat pelindung diri bagi tenaga kesehatan salah satunya ialah perawat.

Pencegahan ke kecelakaan kerja dapat dilakukan dengan (1) pengamatan resiko bahaya di tempat kerja, (2) melakukan setiap tindakan dan pelaksanaan sesuai dengan SOP secara benar di tempat kerja, (3) pengendalian faktor bahaya di tempat kerja, (4) peningkatan pengetahuan tenaga kerja terhadap keselamatan kerja dan (5) pemasangan peringatan bahaya kecelakaan di tempat kerja. Selain itu upaya pencegahan kecelakaan kerja juga perlu disediakan sarana untuk menanggulangi apabila terjadi kecelakaan kerja, contohnya seperti penyediaan $\mathrm{P} 3 \mathrm{~K}$, penyediaan peralatan dan dan perlengkapan tanggap darurat.

Dari hasil penelitian dapat disimpulkan bahwa perawat yang tidak mengetahui dan tidak memahami tentang penerapan $\mathrm{K} 3$ di rumah sakit, memiliki peluang besar untuk tidak melaksanakan penerapan K3 di rumah sakit dibandingkan kan perawat yang mengetahui dan memahami penerapan K3 di rumah sakit.

Hasil penelitian ini mendukung pernyataan sebelumnya yakni, kurangnya pengetahuan tentang penerapan K3, memungkinkan untuk terjadinya peluang kecelakaan kerja sebesar 5 kali dibandingkan dengan perawat yang memiliki pengetahuan tentang K3 RS dengan baik. Jika setiap pekerja mempunyai pengetahuan yang baik tentang yang penerapan K3 di rumah sakit, maka resiko terjadinya penyakit akibat kerja dan kecelakaan akibat kerja akan terhindar atau berkurang.

Yang perlu dilakukan perawat dalam penerapan K3 di rumah sakit salah satunya adalah menerapkan prinsip dari K3RS, yakni perawat diharapkan mampu untuk meningkatkan kenyamanan, keamanan, dan keselamatan pasien. Perawat perlu mengetahui hak dan kewajibannya sebagai perawat dan hak dan kewajiban pasien. Salah satu hak pasien selama dirawat di Rumah Sakit ialah mendapatkan kualitas perawatan yang baik sehingga lama rawat pasien di Rumah Sakit berlangsung dengan cepat.

Penerapan K3RS oleh perawat di rumah sakit dapat mempengaruhi kualitas perawat, kenyamanan pasien, maupun juga citra rumah sakit. Peranan perawat dalam pelaksanaan K3RS di Rumah Sakit juga berpengaruh pada kepuasan pasien, terutama pada pelaksanaan tindakan perawatan kepada pasien. Melalui komunikasi terapeutik, perawat sudah menerapkan K3 di rumah sakit kepada pasien, dimana hal ini yang dapat mempengaruhi kenyamanan pasien. Pasien yang akan menjalani 
proses perawatan yang lama dan cukup berat, akan mengalami kecemasan dan ketidak nyamanan. Perlu dilakukan komunikasi oleh perawat untuk kenyamanan pasien di Rumah Sakit.

Perawat diharapkan mampu untuk meningkatkan keamanan, dan keselamatan pasien melalui penerapan Kewaspadaan standar seperti penggunaan Alat Pelindung Diri (APD). APD merupakan suatu kelengkapan perangkat yang digunakan oleh tenaga kesehatan untuk melindungi dirinya dari potensi bahaya, paparan risiko serta kecelakaan kerja yang kemungkinan dapat terjadi di tempat kerja.

Pemakaian alat pelindung diri merupakan upaya untuk menciptakan keselamatan dan kesehatan kerja bagi perawat beberapa ruangan perawatan rumah sakit. Penggunaan APD dalam program K3RS pada suatu Rumah Sakit seringkali dikaitkan dengan pencegahan infeksi bag petugas kesehatan terutama perawat. APD digunakan oleh tenaga medis, pasien, pengunjung maupun pendamping pasien untuk melindungi dirinya dari mikroorganisme yang terdapat pada suatu tempat pelayanan kesehatan yang biasanya digunakan pada saat petugas kesehatan melakukan tindakan kepada pasiennya. Penggunaaan APD oleh perawat digunakan untu mencegah terjadinya infeksi bagi perawat saat dimulainya tindakan kepada pasien. Tidak hanya bagi petugas kesehatan, tetapi juga bagi pengunjung agar tidak terpapar bahaya infeksi dari pasien lain.

Melalui pengetahuan dan pemahaman yang baik, setiap individu dapat mendukung terlaksananya K3 di rumah sakit dengan baik. Yang pada akhirnya jika setiap pekerja di rumah sakit mampu melaksanakan kebijakan K3 dengan baik maka, resiko terjadinya penyakit akibat kerja dan kecelakaan akibat kerja akan terhindar atau berkurang.

Pentingnya sikap dan tindakan perawat terhadap penerapan standar manajemen Keselamatan dan Kesehatan Kerja di rumah sakit.

Pihak manajemen rumah sakit menjadi bagian yang penting dalam penerapan dan pelaksanaan K3 di rumah sakit. Pihak manajemen menjadi penentu jalannya kebijakan K3 di rumah sakit atau berhentinya penerapan kebijakan K3 di rumah sakit. Menurut Honda dkk ( 2014 ), terdapat hubungan yang signifikan antara sikap perawat terhadap pencegahan cedera atau kecelakaan akibat benda tajam dan terjadinya cedera akibat benda tajam. Perawat yang memiliki sikap negatif terhadap pencegahan cedera benda tajam hampir dua kali cenderung terkena cedera dibandingkan dengan perawat yang bersikap positif terhadap pencegahan cedera benda tajam. Hasil penelitian 
ini mendukung penelitian sebelumnya yang menyatakan bahwa sikap ada hubungannya dengan kejadian kecelakaan kerja.

Penelitian ini membuktikan bahwa sikap yang kurang memberikan respon terhadap penerapan K3 di rumah sakit mempunyai peluang sebesar 8 kali dapat menyebabkan kecelakaan kerja dibandingkan dengan sikap yang baik dan respon terhadap penerapan K3 di rumah sakit. Penting Seorang perawat ataupun petugas Rumah Sakit agar ikut ambil alih dalam pelaksanaan penerapan K3 di rumah sakit agar kecelakaan akibat kerja dan penyakit akibat kerja dapat dikurangi.

Dari hasil penelitian dapat disimpulkan bahwa pentingnya sikap dan tindakan perawat dalam ikut melaksanakan penerapan K3 di rumah sakit. Perawat dan tenaga kesehatan lainnya yang mempunyai tindakan yang baik terhadap penerapan K3 di rumah sakit pada saat bekerja menggunakan APD seperti handscoon, masker dan penutup kepala bagi setiap tenaga kesehatan yang memberikan pelayanan di dalam ruangan dan bagi petugas kebersihan menggunakan sarung tangan, topi sebagai penutup kepala sarung tangan dan masker untuk mencegah terjadinya infeksi nosokomial di lingkungan rumah sakit.

Potensi KAK yang terbesar disebabkan kesalahan atau kelalaian dari karyawan yang tidak menggunakan APD saat bekerja. Pentingnya sikap perawat yang baik dan merespon penerapan K3 dan tindakan perawat yang mendukung penerapan K3 Melalui penggunaan APD dan dan mengikuti prosedur tindakan dengan baik menunjang setiap program penerapan K3 di rumah sakit. Tindakan menggunakan APD dalam bekerja menjadi upaya penerapan K3 di rumah sakit untuk memberikan jaminan keselamatan dan meningkatkan derajat kesehatan para pekerja dengan cara pencegahan kecelakaan dan penyakit akibat kerja.

\section{Penutup}

Penerapan dan pelaksanaa K3 di rumah sakit dipengaruhi dari berbagai aspek, salah satunya tenaga kerja di rumah sakit contohnya perawat. Perawat menjadi salah satu factor penting dalam keberhasilan penerapan kebijakan K3 di rumah sakit. Perawat dituntut untuk dapat memberikan pelayanan kesehatan yang optimal dan berkualitas tanpa melupakan tingkat kesehatan dan keselamatan bagi pemberi asuhan keperawatan dan keselamatan pasien. Pentingnya peranan perawat dalam menjamin Keselamatan Kesehatan Kerja diri perawat dan pasiennya. Perawat diharapkan mampu untuk meningkatkan keamanan, dan keselamatan pasien melalui tetap memperhatikan dan melakukan tindakan asuhan keperawatan sesuai Standar Pelaksanaan 
Operational dan pengendalian factor bahaya di tempat kerja yang merupakan sudah menjadi bagian dari penerapan dan pelaksanaan K3 di rumah sakit oleh perawat.

\section{Daftar Pustaka}

Mongilala W. Fayren, dkk. 2018. Analisis Pelaksanaan Program Kesehatan Kerja di Puskesmas Sonder Kabupaten Minahasa. Jurnal KESMAS. 7 ( 5) .

Ivana azza, dkk. 2014. Analisa Komitmen Manajemen Rumah Sakit (RS) Terhadap Keselamatan Dan Kesehatan Kerja (K3) Pada RS Prima Medika Pemalang. Jurnal kesehatan masyarakat (eJournal). 2 ( 1 ) : 35-41.

Nazirah Riska, Yuswardi. 2017. Perilaku Perawat Dalam Penerapan Manajemen Kesehatan dan Keselamatan Kerja (K3) di Aceh. Idea Nursing Journal. 8 ( 3 ).

Mantir Ezra Z. R. Abiam, dkk. 2020. Faktor psikologi dan perilaku dengan penerapan manajemen keselamatan dan kesehatan kerja di rumah sakit. Indonesian Journal of Public Health and Community Medicine . 1( 3) : 19-27.

Ernawati, N., \& Nurlelawati, E. (2017). Faktor-Faktor Yang Berhubungan Dengan Pelaksanaan Penerapan K3 Pada Tenaga Kesehatan di RSIA Permata Sarana Husada Periode Februari 2015. Jurnal Akademi Keperawatan Husada Karya Jaya. 3 (1) 12-18.

Putri A.S. 2013. Perbandingan Tingkat Kinerja Keselamatan Dan Kesehatan Kerja Sebelum dan Sesudah Penerapan OHSAS 18001 di PT. Phapros, Tbk. Jurnal Bisnis Strategi. 22 ( 1 ).

Fitriana, Y., \& Pratiwi, K..2018. Pelaksanaan Patient Safety di Rumah Sakit Umum Daerah dan rumah sakit umum swasta bantul berdasarkan ketentuan undang-undang nomor 44 tahiun 2009 tentang rumah sakit. Jurnal Kebidanan. 7(1): 28-39.

Firawati. 2012. Pelaksanaan Program Keselamatan Pasien di RSUD Solok. Jurnal Kesehatan Masyarakat. 6 (2).

Harus, B. D.(2015). Pengetahuan Perawat Tentang Keselamatan Pasien dengan Pelaksanaan Prosedur Keselamatan Pasien Rumah Sakit (KPRS) di Rumah Sakit Panti Waluyu Sawahan Malang. Jurnal CARE. 3 (1). 
Runtu, L. G., Haryanti, F., \& Rahayujati, T. B.. 2013. Faktor-Faktor yang Berhubungan dengan Perilaku Perawat dalam Penerapan Universal Precautions di RSUP Prof. Dr. RD Kandou Manado. Jurnal Ilmiah Perawat Manado (Juiperdo). 2 ( 1 ).

Simamora, R. H. (2018). Buku ajar keselamatan pasien melalui timbang terima pasien berbasis komunikasi efektif: SBAR. Medan: USUpress.

Simamora, R. H. (2019). Buku ajar pelaksanaan identifikasi pasien. Uwais Inspirasi Indonesia. 